HISPANIA. Revista Española de Historia, 2010, vol. LXX, núm. 236, septiembre-diciembre, págs. 661-686, ISSN: 0018-2141

\title{
LA CÁMARA DE CASTILLA, EL REY Y LA CREACIÓN DE TÍTULOS NOBILIARIOS EN LA PRIMERA MITAD DEL SIGLO XVIII
}

\section{María del Mar FeliCes de la Fuente \\ Universidad de Almería}

RESUMEN: A lo largo de la primera mitad del siglo XVIII — continuando con la tendencia que venía apreciándose desde el siglo anterior-, fue imponiéndose el decreto ejecutivo o decisivo del rey en lo relativo a la concesión de los títulos nobiliarios, reduciéndose por tanto el número de memoriales de solicitud que fueron remitidos a la Cámara de Castilla para ser examinados y, posteriormente, elevados al monarca para que resolviera. El predominio del decreto ejecutivo — que implicó, en ocasiones, la ausencia de control social sobre los titulados - y la marginación de la Cámara como institución encargada, en teoría, de velar por las circunstancias de los pretendientes a estos honores, llevaría consigo el ennoblecimiento de diversos individuos que, carentes de los méritos y calidades requeridos, lograrían situarse en lo más alto de la jerarquía social.

Palabras Clave: Felipe V. Títulos nobiliarios. Cámara de Castilla. Decreto ejecutivo. Venalidad. Ascenso social.

\section{THE CHAMBer OF CASTILE, THE KING AND THE CREATION OF NOBILITY TITLES IN THE} FIRST HALF OF THE $18^{\text {TH }}$ CENTURY

ABSTRACT: Along the first half of the 18th century - continuing with the trend that was observed from the previous century-, there was imposed the executive or decisive decree of the king in the relative thing to the grant of the pertaining to nobility titles, diminishing therefore the number of briefs of request that were sent to the Chamber of Castile to be examined and, later, raised up to the monarch in order that he was resolving. The predominance of the executive decree — that implied, sometimes, the absence of social control on the graduates - and the marginalization of the Chamber as entrusted institution, theoretically, to guard over the

María del Mar Felices de la Fuente es becaria de Investigación F.P.U. del Ministerio de Educación, Universidad de Almería. Dirección para correspondencia: Departamento de Historia, Geografía e Historia del Arte, Universidad de Almería, Carretera Sacramento, S/N, La Cañada de San Urbano, C.P. 04120 - Almería (España). Correo electrónico:fdm072@ual.es. 
circumstances of the claimants to these honors, would take with it the ennoblement of diverse individuals who, lacking in the merits and qualities needed, would manage to place in the highest of the social hierarchy.

KeY WORDS: Philip V. Nobility titles. Chamber of Castile. Executive decree. Venality. Social ascent.

«La generosidad y liberalidad de reyes y príncipes en ningún momento brilla más que cuando a súbditos y vasallos, que han hecho méritos ante ellos y se muestran totalmente inclinados y dispuestos a respetar a su Rey, los condecoran y recompensan con favores y gracias y los elevan y enaltecen a un grado más alto de excelencia y dignidad, especialmente si todo ello va acompañado por la nobleza de sangre, la inclinación al servicio del Rey y una elevada e ínclita honestidad [...]»1.

Hasta el momento, la historiografía relativa al estamento nobiliario se ha centrado en el estudio de diversos aspectos como el régimen señorial, la historia social y política de la nobleza, los ámbitos cortesanos, la cultura nobiliaria y biografías sobre algunos personajes, pero apenas ha abordado una cuestión fundamental como es el procedimiento de obtención de los títulos nobiliarios. El conocimiento y análisis de este proceso se hace imprescindible en cuanto que revela las vías por las que circularon las solicitudes de estos honores hasta llegar al rey, la importancia que tuvo - para una resolución favorable - contar con el influjo de individuos cercanos a su persona, el recorrido administrativo y burocrático que siguieron las peticiones hasta su aprobación o denegación, el mayor o menor control social que se ejerció sobre los pretendientes — en base a dicho recorrido-, los organismos que estuvieron encargados de su tramitación, y cómo no, la decisión real como determinante —a pesar del disentimiento ocasional con la Cámara de Castilla - en la concesión de estas gracias.

A partir del presente trabajo, hemos comprobado que los títulos nobiliarios pudieron circular a través de dos vías diferenciadas — como expondremos más adelante-, cuyo empleo estuvo íntimamente ligado a la voluntad real, que determinaba si un título debía tramitarse de un modo u otro. Uno de los cauces de circulación fue la Cámara de Castilla ${ }^{2}$, institución encargada histórica-

* Siglas utilizadas:

AGMJ, Archivo General del Ministerio de Justicia; AHN, Archivo Histórico Nacional de Madrid; AGS, Archivo General de Simancas; AGI, Archivo General de Indias; leg. (legajo); exp. (expediente); inv. (inventario); r. (recto); v. (vuelto).

${ }_{1}$ AGMJ, leg. 170-2, exp. 1475. Expediente del título nobiliario de Marqués de Eguaras (1703).

2 Esta institución y sus funciones han sido estudiadas, entre otros, por DE DiOS DE DiOS, Salustiano, «El ejercicio de la gracia regia en Castilla entre 1250 y 1530. Los inicios del Consejo de la Cámara", Anuario de historia del derecho español, tomo LIX (1990), págs. 323-352; Gracia, merced y patronazgo real. La Cámara de Castilla entre 1474-1530, Madrid, Centro de Estudios Constitucionales, 
mente de los asuntos de gracia y merced - ambos estrictamente dependientes de la voluntad regia- y Patronato Real, y de expedir, entre otros, los despachos de los títulos nobiliarios. La otra vía para hacerse con este honor — que funcionó de forma paralela a la anterior - fue la del decreto ejecutivo, por medio del cual el rey otorgaba títulos nobiliarios prescindiendo de la consulta de la Cámara de Castilla.

No conocemos con exactitud los criterios que siguió el monarca para disponer que la solicitud de un título nobiliario - que le habría llegado a través de diversas instancias - fuera consultada o no, pero lo cierto es que mientras que algunos de estos títulos los concedió por decreto ejecutivo, otros los mandó consultar por la Cámara de Castilla para que ésta le informara sobre las calidades del sujeto y le advirtiera sobre la conveniencia o no de otorgar tan alto honor. Probablemente, el hecho de que una solicitud pasase por la Cámara pudo estar relacionado con el desconocimiento por parte del soberano de las circunstancias sociales del pretendiente que solicitaba la merced, motivo por el cual se valdría de esta institución para asesorarse acerca de si debía conceder o denegar el título nobiliario. Por otro lado, el empleo del decreto ejecutivo, también a modo de hipótesis, pudo ser la vía escogida por el rey para conceder mercedes nobiliarias a aquellos individuos que le hubieran servido en los diversos ámbitos de la Monarquía, que hubieran realizado prestaciones harto provechosas para la Corona — como es el caso de los «servicios pecuniarios»—, o que contaran con la influencia de determinados individuos, próximos a su persona, que pudieran favorecer la concesión.

Si bien durante la primera mitad del siglo XVIII las solicitudes de títulos nobiliarios circularon a través de ambas vías, cabe destacar que la mayoría de estos honores fueron otorgados por decreto ejecutivo del rey, lo cual implicó una más que notoria marginación de la Cámara de Castilla.

\section{ANTECEDENTES EN LA TRAMiTACIÓN DE TÍTULOS NOBILIARIOS}

Los asuntos de gracia y merced, antes de la creación de la Cámara de Castilla, estuvieron reservados al Consejo Real, institución que quedó constituida

1993; ÁlvareZ-COCA, María Jesús, «La Corona de Aragón: documentación en el Consejo y la Cámara de Castilla (1707-1834). Fuentes en el Archivo Histórico Nacional», Hispania, XLIX, 173 (1989), págs. 895-948; «La Cámara de Castilla: Secretaría de Gracia y Justicia», Cuadernos de Historia Moderna, 15 (1994), págs. 279-296; «La Cámara de Castilla: Secretaría de Gracia y Justicia. Problemas archivísticos e investigación histórica», en: SCHOLZ, Johannes-Michael (coord.), El tercer poder: hacia una comprensión histórica de la justicia contemporánea en España, Alemania, Vittorio Klostermann, 1992, págs. 1-32; GONZÁLEZ FUERTES, Manuel Amador, La organización institucional de la Cámara de Castilla en la época Borbónica, Córdoba, Servicio de Publicaciones Universidad de Córdoba, 2002; «La Cámara de Castilla y el Real Patronato (1733-1759): de la prepotencia a la impotencia», Brocar: Cuadernos de investigación histórica, 25 (2001), págs. 75-108. 
como tal por unas primeras Ordenanzas dadas en 1385, a partir de las cuales se le encomendaba la tarea de consultar con el rey lo relativo a gracia, merced y Patronato Real ${ }^{3}$. No se sabe con exactitud cuándo nació la Cámara de Castilla ni cuándo se institucionalizó como órgano de consulta, encargado de la tramitación de asuntos de gracia, pero lo cierto es que durante el reinado de los Reyes Católicos se dieron circunstancias determinantes para su consolidación. Las materias anteriormente citadas comenzaron a tramitarse de forma habitual a través de un pequeño consejo, formado por alguno de los consejeros reales y secretarios, y se desarrolló, además, lo que Salustiano de Dios ha denominado como la "vía de Cámara» ${ }^{4}$, separada de la del Consejo —y diferenciada de las vías de expediente y de justicia-, por la que circulaban las consultas relativas a estas materias, que se hacían llegar al rey para que decidiera en última instancia. Según este autor, hacia 1520 se hablaba ya en Castilla del Consejo de la Cámara 5 , y para 1528 Carlos I daba las primeras instrucciones que vendrían a organizar el funcionamiento de esta incipiente Cámara de Castilla ${ }^{6}$, desdoblada por entonces en dos, debido a sus continuos viajes por los territorios europeos ${ }^{7}$.

Tras una serie de disposiciones que se sucedieron después de 1528, finalmente, el 6 de enero de 1588, se consolidaría la Cámara de Castilla como un organismo separado del Consejo de Castilla, aunque vinculado íntimamente a éste $^{8}$. La instrucción de 1588 establecía que el presidente del Consejo Real también presidiera la Cámara, y que en ella se vieran todos los asuntos relativos al patronazgo real de la Iglesia y a la provisión y nombramiento de personas para las plazas de los Consejos, Chancillerías, Audiencias y demás oficios de justicia. Asimismo, se creaban tres secretarías — con anterioridad sólo había existido una, la Secretaría de Cámara-, dependientes de la Cámara de Castilla, para tramitar todas sus competencias: la secretaría del Real Patronato, la de Gracia, y la de Justicia, quedando encargada la de Gracia de despachar, entre otros, los títulos de duques, marqueses y condes 9 .

A pesar del intento de regular y sistematizar las atribuciones de la Cámara a partir de la citada Instrucción, hubo cuestiones referentes a su funcionamiento y competencias que no quedaron definidas del todo, como las materias de gracia y merced, aunque sabemos, por los estudios de Salustiano de Dios, que

3 De Dios De Dios, Salustiano, El Consejo Real de Castilla (1385-1522), Madrid, Centro de Estudios Constitucionales, 1982, pág. 345.

${ }^{4}$ De Dios De Dios, Salustiano, El Consejo Real..., págs. 345-348.

5 De Dios De Dios, Salustiano, Gracia, merced y patronazgo real..., pág. 127.

${ }^{6}$ De Dios De Dios, Salustiano, El Consejo Real..., pág. 347; también GonZÁlez FuerTes, Manuel Amador, La organización institucional..., pág. 37.

7 «Una en Castilla junto con los virreyes o gobernadores y otra en la Corte itinerante de Carlos I», cif. en GonZÁLEZ FueRTES, Manuel Amador, La organización institucional..., pág. 37.

8 Escudero López, José Antonio, «El Consejo de la Cámara de Castilla y la reforma de 1588», Anuario de historia del derecho español, tomo LXVII, volumen II (1997), pág. 925.

9 Gómez Rivero, R., «Cámara de Castilla (1588-1598)», Anuario de historia del derecho español, tomo LXX (2000), pág. 142. 
entre las facultades de la Cámara durante estos primeros años estuvo la de consultar las peticiones de títulos nobiliarios que se le hacían llegar mediante la vía de Cámara ${ }^{10}$, las cuales serían posteriormente presentadas al rey para que resolviera sobre la concesión.

No obstante, desde el siglo XVI el rey intervendría en el despacho de estos y otros asuntos, en teoría concernientes a la Cámara de Castilla, mediante lo que De Dios ha denominado «actuaciones de hecho del rey», a través de las cuales, por cédula o decreto, suspendía o anulaba las acciones de este organismo alterando así su funcionamiento ordinario. De este modo, frente a procedimientos normalizados, el monarca podía imponer su voluntad en cualquier momento, prescindiendo de la consulta de la Cámara y alterando las reglas establecidas.

\section{LA CONCESIÓN DE TÍTULOS NOBILIARIOS EN LA PRIMERA MITAD DEL SIGLO XVIII: PROCEDIMIENTOS}

Durante el Antiguo Régimen funcionó lo que diversos autores han denominado como la «economía de la merced» ${ }^{11}$, consistente en que el individuo que servía al rey lo hacía movido por la pretensión de obtener a cambio una merced - ya fuera económica u honorífica_, del mismo modo que el rey premiaba a sus servidores para generar a su vez más favores por parte de ellos y atraer más adeptos que pudieran servirle. Esta idea de servir para ser recompensado, y de recompensar para obtener más servicios, fue la que estructuró las relaciones políticas entre reyes y súbditos a lo largo de la Edad Moderna, de tal modo que ambas partes tenían la obligación de hacerse prestaciones mutuas, manteniendo así la cohesión social. Pedir una merced -en este caso, una merced nobiliaria - a cambio de servicios prestados, fue una práctica habitual entre los súbditos del rey, pues se sentían autorizados a ello por haberle asistido.

La solicitud de un título nobiliario se iniciaba cuando el pretendiente, bien por sus propios medios o a través de un agente de corte, hacía llegar al rey un memorial - probablemente a través de diferentes instancias tales como los

${ }^{10}$ De Dios De Dios, Salustiano, Gracia, merced y patronazgo real..., pág. 400.

${ }^{11}$ Hespanha, Antonio Manuel, La gracia del derecho. Economía de la cultura en la Edad Moderna, Madrid, Centro de Estudios Constitucionales, 1993, págs. 151-176. Al respecto, son importantes además los trabajos de: Olival, Fernanda, «La economía de la merced en la cultura política del Portugal moderno», en ARANDA PÉREZ, Francisco José, Rodrigues, José Damião (eds.), De Re Publica Hispaniae. Una reivindicación de la cultura política en los reinos ibéricos en la primera modernidad, Madrid, Silex, 2008, págs. 389-407; BRAvo LozANO, Jesús, "Gracia y merced en época de desgracias. Cámara y vida cotidiana en el reinado de Carlos II», en BRAvo LOZANO, Jesús (ed.), Espacios de poder: Cortes, Ciudades y Villas (s. XVI - XVIII), vol. I, Madrid, Universidad Autónoma, 2002, págs. 101-121; De Dios De Dios, Salustiano, «El ejercicio de la gracia regia en Castilla entre 1250 y $1530 \ldots »$. 
Consejos, las Secretarías del Despacho, las secretarías de la Cámara de Castilla, cortesanos, etcétera- donde exponía, normalmente, sus méritos y servicios, los de sus antepasados, su linaje y la posesión de rentas suficientes para mantener «con decencia» el título. La intervención de agentes mediadores en estos trámites se hizo fundamental para que las pretensiones del solicitante llegasen a buen término, pues se encargaban de presentar los memoriales en las instancias correspondientes, de velar por la resolución favorable de los mismos y de hacer cursar una y otra vez las solicitudes de sus representados, en caso de que estas fueran denegadas. Estos intermediarios solían influir positivamente en la tramitación de las peticiones ya que conocían en profundidad los entresijos burocráticos y el funcionamiento de las instituciones administrativas, e incluso formaban parte de activas redes de poder que favorecían la obtención de la merced $^{12}$.

Cuando las peticiones de títulos nobiliarios llegaban hasta el monarca, era él mismo quien optaba por enviar el memorial a la Cámara de Castilla, para que ésta le diera su parecer acerca de la concesión o denegación de la merced - vía consultiva - o bien, por emitir un decreto ejecutivo, prescindiendo de la consulta a la Cámara, mediante el cual concedía el título nobiliario solicitado - vía ejecutiva o decisiva-. No obstante, suponemos que debió haber peticiones que fueron rechazadas desde el principio, por lo que quedarían excluidas de ser tramitadas por ambas vías.

Los motivos de por qué unos títulos nobiliarios fueron consultados por la Cámara de Castilla y otros no, son difusos y desconocidos. Como hipótesis, podemos apuntar que es probable que algunos de los memoriales consultados hubieran sido previamente dirigidos a las secretarías de la Cámara, y por ello fueron tramitados por esta vía. Asimismo, es posible que el rey se valiera de este Consejo, ocasionalmente, para informarse acerca del solicitante que le había remitido un memorial pidiendo una merced nobiliaria. Fuera como fuese, la realidad es que a lo largo de la primera mitad del siglo XVIII, en que Felipe V concedió aproximadamente 320 Títulos de Castilla, la mayoría de las concesiones se realizaron a partir de un decreto ejecutivo. Significativo al respecto es que de los 265 títulos nobiliarios en que hemos podido constatar la vía exacta de tramitación, tan sólo 62 fueron consultados por la Cámara de Castilla —lo que supone un $23 \%$ - mientras que el resto, concretamente 205 títulos - 0 lo que es lo mismo, el $77 \%$ - fueron concedidos a través de la «vía ejecutiva» o «vía del decreto». Igualmente hemos comprobado que conforme avanzó la centuria fue reduciéndose el número de memoriales de solicitud que fueron consultados por la Cámara, pues mientras que en la primera mitad del reinado

12 Vid. GonZÁLEZ FuerTes, Manuel Amador, La organización institucional..., págs. 161-163; ÁlvareZ-Ossorio AlvariÑo, Antonio, «El arte de medrar en la Corte: rey, nobleza y el código del honor», en: Chacón Jiménez, Francisco, Hernández Franco, Juan (eds.), Familias, poderosos y oligarquías, Murcia, Universidad de Murcia, Servicio de Publicaciones, 2001, pág. 60. 
— desde 1701 a 1723 - se consultaron 41 solicitudes de títulos nobiliarios, en la segunda mitad — desde 1724 a 1746 - serían 21 los memoriales examina$\operatorname{dos}^{13}$. De este modo, el decreto ejecutivo se acabó imponiendo finalmente en la concesión de títulos nobiliarios, quedando la Cámara de Castilla relegada a un segundo plano al imponerse de forma abrumadora la voluntad regia, sobre todo cuando se trataba de ennoblecer a individuos de dudosas calidades - que normalmente le habían servido con dinero- cuyas solicitudes de títulos nobiliarios, si hubieran corrido por la Cámara de Castilla, probablemente habrían obtenido un dictamen desfavorable.

\subsection{La vía consultiva de la Cámara de Castilla}

Cuando el monarca decidía remitir el memorial de solicitud de un título nobiliario a la Cámara de Castilla, para que lo examinara y posteriormente diera su parecer informando favorablemente o no sobre la petición, lo hacía a través de la secretaría de Cámara, emitiendo una orden dirigida al presidente de la Cámara de Castilla gobernador a su vez del Consejo de Castilla. Habitualmente, el peticionario, junto a su memorial, incluía una relación de méritos y servicios a la que solía adjuntar certificaciones oficiales que los corroboraban. Si los méritos expuestos no eran suficientes o no estaban del todo justificados, según las exigencias de la Cámara, ésta mandaba despachar una cédula de diligencias para saber si efectivamente concurrían en el solicitante las calidades y requisitos expresados. Mientras que se sustanciaban esas diligencias, la tramitación del expediente quedaba en suspenso, ordenando entonces la Cámara, a través de su secretaría, que se enviara al solicitante una orden requiriéndole más información. Normalmente, la tarea de testimoniar e informar fue encomendada a las autoridades locales - corregidores, Ayuntamientos-o judiciales - Audiencias y Chancillerías-, por ser éstas las que, supuestamente, advertirían de modo más fidedigno sobre las circunstancias del pretendiente. No obstante, en otros casos, la Cámara no mandó expedir cédulas de diligencias, sino que simplemente excusó la pretensión del interesado. Cuando la información era completada según los requerimientos de la Cámara, el secretario correspondiente volvía a presentar la solicitud a los camaristas, continuando así con el proceso consultivo.

El parecer de la Cámara se enviaba al rey mediante una consulta que se le hacía llegar a través de la secretaría de Cámara y, una vez adoptada la resolución real, ésta regresaba a la Cámara por la misma vía de la secretaría. La

${ }^{13}$ Revisadas las consultas de gracia conservadas en la sección Consejos del Archivo Histórico Nacional —relativas al periodo 1701-1746, que se corresponden con los legajos 4.471-4.515observamos que a partir de la década de los años veinte las solicitudes de títulos nobiliarios consultadas se van reduciendo progresivamente hasta quedar anulada prácticamente la Cámara en el proceso de tramitación de los títulos nobiliarios. 
decisión regia podía estar en concordancia o no con lo propuesto por la Cámara, aunque siempre debería ser acatada y cumplida como el monarca había ordenado.

En caso de ser favorable la resolución, la Cámara trasladaría los informes pertinentes a la secretaría para que informara al solicitante de la concesión. Éste, una vez enterado, bien por sí mismo o por medio de un poderhabiente, remitiría al secretario de la Cámara la denominación escogida para el título nobiliario, debiendo sacar además del despacho correspondiente de conde o marqués, el de vizconde, que desde 1631, era obligatorio expedir previamente ${ }^{14}$. La tramitación del despacho implicaba que el agraciado debía pagar los derechos de expedición ${ }^{15}$, consistentes en el pago de la media anata — que sumaba 2.250 ducados, 1.500 por el título de conde o marqués, y los 750 restantes por el de vizconde-, y los derechos de la Real Capilla, monto que ascendía a 2.400 reales de vellón. A esta cantidad habría de añadírsele la satisfacción anual del impuesto de lanzas, establecido en 3.600 reales. La falta de liquidez por parte de algunos ennoblecidos para hacer frente a estos gastos, llegó a retrasar la expedición de los títulos nobiliarios, de modo que, concedida la merced, no se consideraba oficial hasta que no se sacara el correspondiente despacho.

No obstante, el título nobiliario también podía ser concedido con la relevación del pago de lanzas y medias anatas, exención que respondió normalmente a una dispensa graciosa realizada por el rey, a un desembolso previo por parte del agraciado — cantidad a veces incluida en el precio de compra del título-, o bien, a partir de 1739 , al pago de 160.000 reales mediante los cuales podían redimirse perpetuamente estas mercedes del abono del derecho de lanzas ${ }^{16}$. La relevación perpetua de estos impuestos excusaría al titulado y a sus sucesores de volver a pagarlos.

Por el contrario, si la solicitud de la merced era denegada por la Cámara, o bien quedaba paralizada, por haber resuelto finalmente el rey que «se le tendrá presente», el pretendiente podría volver a iniciar el proceso de petición empleando otros medios - como aumentar sus servicios o verse favorecido por la influencia de otros intermediarios- para lograr tan codiciada distinción. Con el paso de los años, algunas de estas solicitudes que en un principio habían sido denegadas, serían finalmente concedidas por medio de una consulta favorable o a través de un decreto ejecutivo del soberano.

Las solicitudes de títulos nobiliarios informados por la Cámara de Castilla fueron de carácter muy diverso, pues se consultaron tanto peticiones de individuos que contaban con méritos y servicios, como memoriales de personas que previamente habían adquirido su título nobiliario mediando un pago monetario.

${ }^{14}$ La Real Cédula es de 15 de octubre de 1631. Cif. en MAYORALGO y LODO, José Miguel (conde de los Acevedos), Historia y régimen jurídico de los títulos nobiliarios, Madrid, Hidalguía, 2007, pág. 80.

${ }^{15}$ Impuestos creados por Reales Cédulas de 18 de agosto de 1631 y 10 de diciembre de 1632.

16 AGI, Lima, leg. 1277. 


\subsubsection{Consultas sobre méritos y servicios}

De los memoriales remitidos a la Cámara predominaron —más de la mitad- aquellos en los que el solicitante exponía sus servicios, personales y heredados, a fin de que fueran recompensados con un título nobiliario. Uno de estos títulos, concedido en atención a los méritos y servicios del pretendiente y sus antepasados, fue el de conde de Villapineda, merced otorgada a Pedro Pineda Salinas por consulta de la Cámara de Castilla de 27 de mayo de $1737^{17}$. El solicitante hizo su petición por medio de un memorial que incluía una relación de méritos y una carta de recomendación del cabildo de la ciudad de Sevi$1 l a^{18}$ — del cual formaba parte—, que llegaron a la Cámara por orden del rey de 12 de febrero de 1728. En dicho memorial representaba que era veinticuatro de la ciudad de Sevilla, escribano mayor de su cabildo y ayuntamiento, y que había votado a favor de la prorrogación de millones en 1716 y $1721^{19}$. Hacía mención, además, a los servicios de sus antepasados en diversos empleos políticos y militares de toda distinción, al lustre y esplendor de su Casa, que pertenecía a una de las más antiguas de Sevilla, y a las alianzas que poseía con otras familias de la primera nobleza. En atención a todas aquellas circunstancias, solicitaba Pedro de Pineda un Título de Castilla, con la denominación de conde de Villapineda, "por haber sido esta villa de Gonzalo Pérez Pineda, ricohombre de Castilla y su progenitor» ${ }^{20}$.

Ante tal pretensión, la Cámara, por una primera consulta de 5 de abril de 1728 , estimó que a pesar de ser tan notorio lo que el suplicante representaba, se mandasen despachar las cédulas de diligencias acostumbradas, para que se justificase formalmente su calidad «y los bienes y rentas con que se hallaba para poder mantener con decencia esta dignidad». Aprobada por el rey la petición de informes, estos fueron realizados por Rodrigo Caballero Illanes, Asistente de Sevilla, y posteriormente remitidos de nuevo a la Cámara. El rey, finalmente, de acuerdo con lo propuesto por el órgano consultivo, despachó favorablemente la merced con un «como parece» ${ }^{21}$. Informado Pedro de Pineda

17 AGMJ, leg. 1908, exp. 214-3.

${ }_{18}$ La carta era de primero de julio de 1726, y lo mencionaba «como uno de los capitulares que más se habían destacado en el real servicio, por concurrir en su persona y Casa tan antiguos méritos y esplendor», AGMJ, leg. 1908, exp. 214-3.

19 AGMJ, leg. 1908, exp. 214-3. Sabemos además que obtuvo en 1711 una de las mercedes de hábito concedidas por Felipe V a la ciudad de Sevilla, en agradecimiento a los servicios prestados durante la Guerra de Sucesión. No obstante, desconocemos si finalmente llegó a usar de ella. AGS, Estado, lib. 436. Sobre las mercedes otorgadas en Andalucía tras la Guerra de Sucesión, vid. ANDÚJAR CASTILLO, Francisco, «Servicios para la guerra, mercedes para las oligarquías. Las recompensas de la Guerra de Sucesión en Andalucía», en: BernARdo ArES, José Manuel de (coord.), La sucesión de la monarquía hispánica, 1665-1725 (I). Lucha política en las Cortes y fragilidad económica-fiscal en los Reinos, Córdoba, Servicio de Publicaciones, Universidad de Córdoba, 2006, págs. 43-74.

${ }^{20}$ AGMJ, leg. 1908, exp. 214-3.

${ }^{21}$ AGMJ, leg. 1908, exp. 214-3. 
- por el secretario de la secretaría de Gracia y Justicia de la Cámara de Castilla, por entonces Francisco Javier de Morales - de la concesión del título nobiliario, se dispuso a sacar los despachos, eligiendo la denominación de vizconde de Ballesteros y conde de Villapineda ${ }^{22}$.

Algunos de los memoriales que llegaron a la Cámara habían sido previamente consultados por otros Consejos, como el de Italia o Indias. Esta circunstancia se producía cuando los servicios y méritos de los pretendientes al título nobiliario habían tenido lugar en esos territorios de la monarquía hispánica. Es el caso del marqués de Feria, Francisco Félix Vega Cruzat, quien había desarrollado su carrera política y militar en Italia, como gobernador de Pescara y Barletta, capitán de caballos corazas y maestre de campo ${ }^{23}$. Tras dos consultas realizadas en el Consejo de Italia ${ }^{24}$, se remitieron a la Cámara de Castilla para que diera su parecer al rey sobre la concesión de la merced. En consulta de la Cámara de 17 de septiembre de 1704 propuso que se despachasen cédulas de diligencias para conocer las calidades del referido Francisco Félix Vega. Casi un mes más tarde, por decreto ejecutivo del rey de 13 de octubre de 1704, y prescindiendo de la nueva consulta a la Cámara, que normalmente tenía lugar tras las diligencias, se le concedía el título de marqués de Feria ${ }^{25}$.

La intervención del rey en los procedimientos de la Cámara, alteró en ocasiones su normal funcionamiento, trastocando así el curso que solían seguir las solicitudes de títulos nobiliarios que se tramitaban por esta vía consultiva. Al igual que en el caso del marqués de Feria, fue común que algunos de los títulos que previamente habían sido consultados por la Cámara, se concedieran con posterioridad a través de un decreto ejecutivo del rey. Este procedimiento de concesión se empleó sobre todo en solicitudes que, tras ser consultadas por la Cámara, habían quedado paralizadas tras resolver el rey «se le tendrá presente». Al cabo del tiempo, por requerimientos del peticionario, estas solicitudes podrían volver a ponerse en marcha, y si el monarca lo estimaba oportuno, otorgaría la merced sin nueva consulta, mediando entonces un decreto ejecutivo. Esta casuística la encontramos, por ejemplo, en la concesión del título nobiliario de marqués de Fuente Pelayo a Fernando Matanza Corcuera, en la cual precedieron diversas consultas a la Cámara de Castilla fechadas en 1687, 1694 y $1695^{26}$. La merced no sería otorgada hasta el 5 de diciembre de 1703 , por decreto ejecutivo del rey «en atención a su calidad méritos y servicios y a la aprobación con que los continúa en el corregimiento de Madrid $»^{27}$.

Menos frecuentes fueron las consultas que realizó la Cámara de Castilla sobre títulos nobiliarios que previamente habían sido concedidos por el rey me-

\footnotetext{
22 AGMJ, leg. 1908, exp. 214-3.

23 AHN, Consejos, leg. 8976, exp. 176.

${ }^{24}$ AHN, Consejos, lib. 2753.

${ }^{25}$ AGMJ, leg. 111-2, exp. 1004.

${ }^{26}$ AGMJ, leg. 194-1, exp. 1724.

27 AHN, Consejos, leg. 8976, exp. 162.
} 
diante un decreto ejecutivo. Es significativo el caso de José de Aldaz, marqués de Monte Real, cuyo título nobiliario fue consultado por la Cámara en 1 de abril de 1705 , a pesar de haber sido concedido unos meses antes por decreto de 3 de febrero de 1705. En este caso, la merced se le otorgó como recompensa por la construcción de dos ingenios —además de las fábricas de fundición de armería que ya poseía-, para proveer a los ejércitos de armamento ${ }^{28}$.

En último lugar, hubo un pequeño grupo de tres títulos nobiliarios, otorgados todos en 1705, que fueron concedidos a consulta de la Junta de Asistentes a Cortes, formada por aquellos camaristas que asistían a las mismas. Los agraciados serían Jerónimo Ortiz Sandoval, conde de Mejorada ${ }^{29}$, Francisco Maldonado Rodríguez, conde de Villagonzalo ${ }^{30}$ y Francisco Domonte Robledo, marqués de Villamarín ${ }^{31}$, cuyo mérito común — según consta en sus títulos- fue haber votado en 1702 a favor de la prorrogación del servicio de millones en nombre de sus respectivas ciudades, tal cual se hizo rezar en sus títulos nobiliarios.

\subsubsection{Consultas sobre títulos nobiliarios enajenados}

A la Cámara también llegaron memoriales para que consultara solicitudes de títulos nobiliarios que habían sido previamente vendidos a través de diversas instancias. El papel que debía cumplir esta institución entonces era el de informar al rey de si la merced debía ponerse o no en cabeza del comprador, teniendo en cuenta las circunstancias que concurrían en él. Es el caso, por ejemplo, de algunos títulos enajenados a través de conventos o monasterios, los cuales, una vez concertada la venta con el comprador, redactaban un memorial que se hacía llegar a la Cámara, donde solicitaban la aprobación de la merced nobiliaria en el individuo propuesto. Era entonces cuando la Cámara, por regla general, llevaba a cabo una serie de «diligencias» para conocer las calidades, méritos y servicios del adquiriente. Normalmente, el papel de la Cámara no fue otro que el de confirmar la operación, bien porque las informaciones que le llegaban sobre los pretendientes eran favorables — estando muchas de ellas manipuladas para ocultar las verdaderas calidades y ocupaciones del sujeto, como hemos demostrado para el caso del marqués de Dos Fuentes ${ }^{32}$ - o bien

${ }^{28}$ AHN, Estado, leg. 849.

29 AHN, Consejos, leg. 8976, exp. 244.

30 AHN, Consejos, leg. 8976, exp. 173.

31 AHN, Consejos, leg. 8976, exp. 241. Sobre el ascenso de los Domonte Robledo, vid. VILA Vilar, Enriqueta y LoHmann VillenA, Guillermo, Familia, linajes y negocios entre Sevilla y las Indias. Los Almonte, Madrid, Fundación Mapfre Tavera, 2003.

32 Vid. Felices De LA Fuente, María del Mar, «Del comercio a la nobleza titulada: la compra del título nobiliario de marqués de Dos Fuentes», en: ReY CASTElaO, Ofelia y LóPEZ, Roberto J. (eds.), El mundo urbano en el siglo de la Ilustración, volumen II, Santiago de Compostela, Xunta de Galicia, Consellería de Innovación e Industria, Dirección Xeral de Turismo, 2009, págs. 515-527. 
porque la Cámara, aún estando al tanto de la dudosa naturaleza del ennoblecido, tenía que aprobar la compra ante los requerimientos económicos de las instituciones religiosas.

Reveladora al respecto es la información que se halla en el expediente de concesión del título nobiliario de marqués de Villapalma de Encalada ${ }^{33}$. Se trata de un título en blanco que había otorgado Carlos II al convento de las mercedarias descalzas de Madrid — por resolución a consulta de la Cámara de 22 de julio de 1698 - para que con su producto se hiciese frente a unas obras de reparación ${ }^{34}$. En un primer momento, el beneficio de esta merced corrió a cargo de Juan de Layseca, protector del convento, consejero de Castilla y camaris$\mathrm{ta}^{35}$. Las ofertas que se hicieron entonces por parte de algunos pretendientes para adquirir el título no fueron aceptadas, pues ofrecían sumas muy cortas, comprendidas entre los 60.000 y los 95.000 reales, cuantía esta última que pretendía dar un vecino de Estepa, Francisco Sánchez Pleites ${ }^{36}$. A la muerte de Juan de Layseca, en 1707, la venta del título quedaría en manos del obispo de Gironda, Lorenzo Armengual de la Mota — que por entonces era también obispo de $\mathrm{Cádiz}^{37}$ y presidente del Consejo de Hacienda ${ }^{38}$ —, quien en 1715 informaba de que el convento tenía ajustada la venta en 7.000 pesos escudos con Francisco Zabala Villela, contador de la Santa Cruzada de la ciudad de Lima. El mismo Lorenzo Armengual era consciente de la cortedad de aquel servicio, pues como él mismo expresaba, las necesidades de dinero del convento «y la poca esperanza que puede tener de otro más útil beneficio» precisaban de la voluntad regia para la concesión del título por debajo de los precios de mercado.

Sin embargo, semejante argumento no fue suficiente para que el rey aceptase beneficiar la merced en la referida cuantía, y finalmente el título fue puesto en cabeza de Diego Calvo Encalada Orozco, un sevillano asentado en Indias, caballero de Santiago ${ }^{39}$, que desembolsó los 22.000 ducados requeridos para la obtención del título nobiliario. Una vez acordada la compra entre el convento y Diego Calvo Encalada, la Cámara solicitó informe sobre las calidades del pretendiente a Diego de Zúñiga, consejero de Indias, quien expuso que el suplicante, además de poseer «haciendas de campo muy cuantiosas, que le fructifi-

33 AGMJ, leg. 116-1, exp. 1050.

${ }^{34}$ Andújar Castillo, Francisco y Felices de la Fuente, María del Mar, «Nobleza y venalidad: el mercado eclesiástico de venta de títulos nobiliarios en el siglo XVIII», Chronica Nova, 33 (2007), pág. 151.

35 AGMJ, leg. 116-1, exp. 1050.

36 AGMJ, leg. 116-1, exp. 1050. En otro memorial remitido a la Cámara representó que para mayor aumento daría al convento un efecto de más de 147.000 reales que tenía contra la Real Hacienda. No obstante, a pesar de aumentar la cantidad que ofrecía, la Cámara rechazó beneficiar el título «por no ser dinero prompto».

37 AGMJ, leg. 116-1, exp. 1050.

38 AGS, Gracia y Justicia, leg. 814.

39 AGMJ, leg. 116-1, exp. 1050. 
caban crecidos yntereses, gozando además de una encomienda de indios», contaba con los méritos, servicios y calidades suficientes como para obtener el título nobiliario. Evidentemente, el único mérito que le valió a Diego Calvo la obtención del título fue el pago de los 22.000 ducados, pues de poco le hubiera servido presentar sus «servicios» como comisario general de la caballería del ejército de Chile, diputado del referido ejército, alcalde mayor de Santiago de Chile y corregidor de Colchagua ${ }^{40}$, cargos estos últimos seguramente venales ${ }^{41}$. De este modo, tras un intento fallido de obtener una merced nobiliaria en $1726^{42}$, Diego Calvo Encalada Orozco lograba titularse marqués de Villapalma de Encalada dos años después ${ }^{43}$.

Los títulos nobiliarios para vender se otorgaron a veces con la condición de que el sujeto que adquiriera la merced fuera «de la aprobación de la Cámara», circunstancia que, aunque en teoría parecía otorgarle a esta institución cierto protagonismo en el proceso de concesión, no implicaba más que la consiguiente aprobación y ratificación del título en el sujeto propuesto por la entidad o el particular que vendía.

Muestra de ello es el título que Carlos II concedió a la ciudad de Fuenterrabía — que había quedado destruida tras el asedio francés de 1638-, por consulta de la Cámara de 28 de junio de $1687^{44}$, para beneficiar «en persona que aprobase la Cámara». Esta merced sería adquirida por José Bayona Chacón ${ }^{45}$, un hidalgo natural de La Habana, que se titularía como conde de Casabayona en 1720 tras el pago de 20.000 ducados $^{46}$. Una vez convenida la transacción entre la ciudad y el adquiriente, éste dio memorial a la Cámara solicitando que aprobara la compra del título. La Cámara, por su parte, a trapág. 340.

${ }^{40}$ Espejo, Juan Luis, Nobiliario de la Capitanía General de Chile, Chile, Andrés Bello, 1967,

41 Posiblemente, Diego Calvo Encalada contara ya con una previa experiencia venal antes de hacerse con el título nobiliario. Es significativo que el cargo de corregidor de Colchagua le fuese dado en 28 de diciembre de 1717 por decreto ejecutivo, sistema de concesión que, como ha demostrado Francisco Andújar para el periodo 1704-1711, escondía en numerosos casos un nombramiento por dinero. Vid. ANDÚjAR CASTILlo, Francisco, Necesidad y venalidad: España e Indias, 17041711, Madrid, Centro de Estudios Políticos y Constitucionales, 2008.

42 AGI, Lima, leg. 595. No se le dio curso a su solicitud porque se le previno que debía hacer un servicio pecuniario a cambio de la merced y no lo hizo.

43 AHN, Consejos, leg. 8977, exp. 727. Los despachos del título se expedían en 19 de agosto de 1728.

44 AHN, Consejos, leg. 8977, exp. 276.

45 Sus ocupaciones principales fueron las de alcalde ordinario y alférez mayor de La Habana, además de ejercer como señor jurisdiccional de Santa María del Rosario (Cuba), donde desempeñó los oficios de justicia mayor y teniente a guerra de aquella ciudad y sus territorios limítrofes. En aquellas tierras instituiría, previa cédula real de 4 de abril de 1732, uno de los mayorazgos más importantes del lugar sobre las tierras de Quiebra-hacha y un corral llamado Jiaraco. Vid. ZABALA MEnéndeZ, Margarita, Coronas de Indias, tomo II, Sevilla, Fabiola de Publicaciones Hispalenses, 2006, pág. 372.

46 AHN, Consejos, leg. 8977, exp. 276. 
vés del Secretario de Gracia y Justicia, Francisco Castejón, pidió «reservadamente» a Andrés de Pez, Gobernador del Consejo de Indias, que informara sobre las calidades de dicho sujeto, el cual respondió que en José de Bayona "concurrían todas las circunstancias y lustre que se requería», sobre todo por ser sobrino suyo y del jefe de escuadra D. Fernando Chacón, uno de los primeros caballeros de La Habana ${ }^{47}$. Nada se decía, por supuesto, de que el capital de José de Bayona provenía del cultivo de la caña de azúcar, actividad que lo había convertido en uno de los grandes hacendados de $\mathrm{Cuba}^{48}$. La Cámara, conforme con la información recibida, aprobó la concesión. En este caso, que las pesquisas sobre el comprador se encomendaran a Andrés de Pez — tío del pretendiente-, no debió de ser un hecho intranscendente, pues con toda seguridad a la Cámara hubo de interesarle que éstas fueran positivas para facilitar el proceso de venta - pensemos que el título en blanco llevaba más de treinta años en poder de la ciudad, sin haberse beneficiado - y revalidar la transacción ya efectuada entre el particular y la ciudad. Los informes del gobernador del Consejo de Indias no sólo favorecerían a su sobrino, que logró ennoblecerse, sino también al estatus de toda la familia que a partir de entonces incorporaba al linaje nada menos que un Título de Castilla.

Algunos de los títulos nobiliarios beneficiados por los virreyes que iban a Indias, o por particulares que obtenían una merced en blanco para vender, también fueron consultados. En el caso de los títulos enajenados por virreyes, la institución encargada de llevar a cabo la consulta fue el Consejo de Indias, como ocurrió en los títulos de marqués de Menahermosa (1746)49 y marqués de San Felipe el Real de la Nueva Población del Reino de Chile (1744) $)^{50}$, adquiridos respectivamente por José Llamas Estrada y Diego Quint Riaño. Ambos comprarían al virrey de Perú, José Manso, uno de los seis títulos nobiliarios en blanco que llevó a aquel lugar para beneficiar, y así, con el producto de su venta, construir poblaciones en las que pudieran habitar españoles e indios dispersos en Chile. El precio de estas mercedes ascendería a 20.000 pesos, y se otorgaron con la condición previa de que los aspirantes a ellas debían ser presentados en el Consejo de Indias ${ }^{51}$.

Por su parte, los títulos nobiliarios vendidos por particulares también requirieron en algunos casos de la consulta de la Cámara de Castilla, como ocurrió con el título de conde de la Fuente Roja (1722), o de conde de Cumbrehermosa (1737), que fueron consultados por orden del rey de 11 de noviembre de $1722^{52}$, y 26 de junio de $1737^{53}$, respectivamente, tras ser ajustada la compra-venta entre sus propietarios y los adquirientes.

47 AGMJ, caja. 51-3, exp. 334.

48 Goncalvès, Dominique, Le planteur et le roi. L'aristocratie havanaise et la couronne d'Espagne (1763-1838), Madrid, Casa de Velázquez, 2008, pág. 87.

49 AGMJ, leg. 261-2, exp. 2456.

50 AGMJ, leg. 154-2, exp. 1321.

51 AGI, Títulos de Castilla, leg. 6, fol. 23r.

52 AHN, Consejos, leg. 8977, exp. 292.

53 AHN, Consejos, leg. 8977, exp. 782. 


\subsection{La vía ejecutiva o del decreto decisivo}

El predominio del decreto ejecutivo sobre la vía consultiva no fue algo exclusivo de la primera mitad del siglo XVIII, pues hemos comprobado que en las postrimerías de la centuria anterior, en la última década concretamente, la mayoría de los títulos nobiliarios fueron igualmente otorgados por decreto, correspondiéndose esta preeminencia del decreto con un periodo de venalidad significativo - coincidencia constatada también para otros periodos ${ }^{54}$ - como fue el final del reinado de Carlos $\mathrm{II}^{55}$. Del mismo modo, a partir de unas primeras estimaciones, podemos concluir que durante la segunda mitad del siglo XVIII y siguiendo con la dinámica expuesta, el empleo del decreto ejecutivo en la concesión de mercedes nobiliarias continuaría siendo mayoritario en relación a las solicitudes de títulos que fueron consultadas por la Cámara de Castilla.

$\mathrm{Al}$ igual que en la vía consultiva, los memoriales de solicitud de títulos nobiliarios que fueron otorgados por decreto ejecutivo debieron llegar al monarca a través de diversas instancias, aunque en estos casos el rey no remitía las solicitudes a la Cámara de Castilla para que le informara sobre el pretendiente y le consultara su parecer, sino que decidía por sí mismo sobre la concesión o denegación de la merced. La decisión del monarca era entonces remitida a la Cámara, en forma de decreto ejecutivo dirigido al Presidente del Consejo de Castilla, para que ésta quedara informada de la resolución real y llevara a cabo los trámites necesarios para que se despachase la merced nobiliaria en cabeza de quien el rey había resuelto. Cuando el monarca empleaba este procedimiento para otorgar un título nobiliario, la Cámara se limitaba a obedecer las órdenes que le llegaban desde las instancias superiores, quedando marginada del proceso de concesión. La función que desempeñaba entonces era meramente administrativa, pues aquellas disposiciones eran de aplicación inmediata e irrefutable.

El decreto ejecutivo no fue sólo empleado en la concesión de mercedes nobiliarias, sino también en los nombramientos de los principales agentes del gobierno de la Monarquía, como ha demostrado recientemente Francisco Andújar en su obra Necesidad y Venalidad ${ }^{56}$. En su estudio demuestra cómo durante la primera década del siglo XVIII funcionó una vía reservada o ministerial, fundamentada en el decreto decisivo del rey, por medio del cual se prescindió

54 Para el intervalo de tiempo comprendido entre 1704-1711, vid. ANDÚJAR CASTILLO, Francisco, Necesidad y venalidad... págs. 6-7 y 11.

55 Remitimos a la extensa bibliografía recogida en la publicación más reciente sobre el tema: SANZ TAPIA, Ángel, ¿Corrupción o necesidad?: La venta de cargos de gobierno americanos bajo Carlos II (1674-1700), Madrid, CSIC, 2009.

56 ANDÚJAR CASTILlo, Francisco, Necesidad y venalidad..., pág. 304. Este mismo autor ha constatado el empleo del decreto ejecutivo en el nombramiento de cargos de gobierno en el reinado de Carlos IV. Vid. ANDÚjar CAstillo, Francisco, «Nepotismo, clientelismo y fidelidad. De Floridablanca a Godoy (1789-1798)», Cuadernos de Historia Moderna. Anejos, VII (2008), págs. 179-211. 
de la Cámara a la hora de designar cargos tradicionalmente consultados como eran los de justicia.

Por medio del decreto ejecutivo, el rey otorgó títulos nobiliarios que venían a recompensar prestaciones de diversa índole —incluidos los servicios pecuniarios- que exponemos a continuación.

\subsubsection{Compensación de méritos y servicios}

Una parte de los títulos nobiliarios concedidos por decreto ejecutivo se otorgaron para premiar méritos y servicios. Era el modo que tenía el soberano de recompensar, sin la intervención de la Cámara de Castilla, a aquellos hombres que le habían servido en el gobierno de la monarquía o en la guerra.

El título nobiliario de marqués del Surco es un ejemplo de recompensa a los servicios ejecutados en la Guerra de Sucesión y en la Corte. El agraciado fue el panameño Fernando Suárez de Figueroa, quien por decreto de 6 de julio de 1716 obtuvo la merced de marqués por sus veintitrés años de servicios militares en los ejércitos reales de Flandes e Italia y por las funciones que había desempeñado como teniente de ayo del príncipe Luis ${ }^{57}$. Comenzó su carrera militar como capitán de infantería en Milán ${ }^{58}$, e iría ascendiendo hasta ser nombrado mariscal de campo, y posteriormente gobernador y capitán general de Cartagena de Indias en 1711, cargo que no llegó a desempeñar por estar ejerciendo entonces de teniente de ayo del infante don Luis. Fue nombrado, además, en 1714 comendador de la encomienda del Viso y Santa Cruz, perteneciente a la orden de Calatrava ${ }^{59}$, de la cual era caballero desde $1687^{60}$. Tras la obtención del título nobiliario, prosiguió su ascenso siendo nombrado gentilhombre de Cámara, primer caballerizo del príncipe de Asturias, en $1721^{61}$, y gobernador de la Casa del Infante don Felipe en 172462. Sus servicios fueron certificados por Pedro de Zúñiga Dávila, marqués de Mirabel y conde de Brantevilla, y por Lucas Espínola, ambos tenientes generales de los reales ejércitos ${ }^{63}$.

El decreto ejecutivo sirvió también, como apuntábamos más arriba, para ennoblecer a individuos que habían servido al rey en el gobierno de la monarquía. Ejemplos significativos son los del marqués de Grimaldo o el conde de la Cadena, figuras clave de la administración y las finanzas, respectivamente, en los primeros años del reinado de Felipe V. No vamos a profundizar en sus ca-

\footnotetext{
57 AHN, Consejos, leg. 8977, exp. 257.

58 AHN, Consejos, leg. 16.839.

59 Gaceta de Madrid, 25 de abril de 1713.

60 AHN, Órdenes Militares, Caballeros de Calatrava, exp. 2527.

61 Gaceta de Madrid, 14 de octubre de 1721.

62 Gaceta de Madrid, 22 de febrero de 1724.

63 AGMJ, leg. 279-2, exp. 2671.
} 
rreras, pues existen al respecto algunos estudios monográficos recientes ${ }^{64}$. No obstante, apuntaremos que la vía del decreto fue, en ambos casos, el procedimiento que utilizó el monarca — haciendo uso de su poder absoluto- para concederles un Título de Castilla.

Los múltiples servicios de José Grimaldo por espacio de treinta y siete años en diversos ministerios y su posición privilegiada como hombre de confianza del rey, le valdrían la concesión del título de marqués de Grimaldo por decreto de 8 de octubre de $1714^{65}$. Además, sería recompensado con otros honores como un hábito de la orden de Santiago (1683), una merced de Gentilhombre de Cámara del rey (1714) y el collar de la insigne orden del Toisón de Oro (1724).

Tres años antes, por decreto de 22 de diciembre de $1711^{66}$, concedía el rey idéntica merced a Bartolomé Flon Morales, uno de los principales financieros y prestamistas de la monarquía durante la Guerra de Sucesión ${ }^{67}$, quien había adelantado a la Real Hacienda entre 1700 y 1712 más de cuatro millones de escudos de plata y se había encargado durante la contienda del abastecimiento de los ejércitos con víveres y otros pertrechos ${ }^{68}$. Entre sus méritos para la obtención del título nobiliario, constaba además haber participado en el rescate, en 1702, del oro y dinero que traían dos barcos procedentes de Indias, que tuvieron que arribar forzosamente en Vigo a causa del ataque de los aliados. Logró entonces Flon reunir tropas a su costa, salvar gran parte de aquel tesoro y enviar a Francia a los supervivientes. Junto con estas acciones, y en colaboración con Huberto Hubrecht, consiguió además que parte de ese tesoro pasara a las arcas de la hacienda francesa. Por todo ello, y fundamentalmente por este último servicio, sería recompensado por Luis XIV con una cadena de oro, en recuerdo de la cual tomaría la denominación de conde de la Cadena, título del que sacó despacho en 11 de marzo de $1712^{69}$.

Es revelador que en dicho despacho no se hiciera referencia a su limpieza de sangre o hidalguía, a los servicios de sus antepasados o a la calidad y lustre de su familia, factores fundamentales con los que teóricamente debía contar el solicitante de un título nobiliario. Está claro que cuando las mercedes corrían

64 Entre otros, sobre el marqués de Grimaldo, vid. Castro, Concepción de, A la sombra de Felipe V: José de Grimaldo, ministro responsable (1703-1726), Madrid, Marcial Pons Historia, 2004; REY CABIESES, Amadeo Martín, «El marqués de Grimaldo: un estadista al servicio del Rey Don Felipe V», Anales de la Real Academia Matritense de Heráldica y Genealogía, 8, 2 (2004), págs. 751-784; Muñoz Serrulla, María Teresa, «Don Bartolomé de Flon y Morales, I Conde de la Cadena, finanzas y ascenso social: su participación en la creación y desarrollo del Monte de Piedad de Madrid (s. XVIII)», Hidalguía, 331 (2008), págs. 729-770.

65 AHN, Consejos, leg. 8976, exp. 250.

66 AHN, Consejos, leg. 8976, exp. 229.

67 Vid. Andújar Castillo, Francisco, Necesidad y venalidad..., págs. 102-108.

68 AGMJ, leg. 297-3, exp. 9088.

69 AHN, Consejos, leg. 8976, exp. 229. 
por la vía del decreto ejecutivo, y era el monarca quien hacía valer su decisión, estas consideraciones pasaban a un segundo plano. Conceder un título nobiliario por decreto implicaba para el agraciado no tener que demostrar o justificar sus méritos y calidades. Es por ello que el rey se valdría de la vía del decreto para ennoblecer a individuos de dudosos orígenes sociales, sobre todo cuando medió, como veremos más adelante, el desembolso de una cantidad determinada de dinero. En el caso concreto de Bartolomé Flon, sus ocupaciones previas como financiero y prestamista no fueron impedimento para obtener un Título de Castilla libre de lanzas y medias anatas, pues contaba no sólo con el favor del rey, sino también con las recomendaciones del príncipe de Barbanzón, por entonces Capitán General de Galicia, y del marqués de Blecourt, embajador de Luis XIV.

Además de los méritos y los servicios, las relaciones sociales fueron fundamentales a la hora de obtener una merced nobiliaria. Formar parte de algunas redes de poder e influencia, ya fueran familiares, de parentesco, amistad o patronazgo, es decir, estar vinculado de alguna manera a los sujetos que por entonces movían los hilos del poder y estaban cercanos al monarca, era otro modo de conseguir mercedes ${ }^{70}$, pues a menudo la obtención de honores no corrió a través de «cauces reglados», sino a través de vías más cerradas y secretas, asentadas en las influencias y en las relaciones de poder.

La importancia de los vínculos familiares se hace patente, por ejemplo, en la creación, por decreto de 26 de abril de 172971, del título de marqués de Guerra, otorgado a Antonio Joaquín Guerra Arteaga. Para esta concesión, sus méritos como ministro de capa y espada en el Consejo de Hacienda le fueron reconocidos, y de hecho se hicieron constar en el despacho del título. Sin embargo, lo decisivo serían los méritos de sus tíos - Domingo Valentín Guerra, obispo de Segovia y confesor de la reina Isabel de Farnesio ${ }^{72}$, y Miguel Francisco Guerra, gobernador del Consejo de Hacienda, consejero del Consejo de Castilla, camarista y consejero de Estado-y la influencia que pudieron desplegar sobre la voluntad del soberano al desempeñar cargos tan próximos a la real persona ${ }^{73}$.

Los aspirantes a un título nobiliario conocían la influencia que determinados individuos podían llegar a ejercer sobre quienes tramitaban estas mercedes. Así se entiende que Antonio Álvarez de Bohórquez, marqués de Ruchena por

70 Vid. Imízcoz BeunZA, José María, «Elites administrativas, redes cortesanas y captación de recursos en la construcción social del Estado moderno», Trocadero. Revista del departamento de historia moderna, contemporánea, de América y del arte, 19 (2007), págs. 11-30.

71 AHN, Consejos, leg. 8977, exp. 733.

72 AGS, Dirección General del Tesoro, inv. 13, leg. 1, exp. 2.

73 La cercanía de Miguel Francisco Guerra al monarca fue tal, que llegó a formar parte de los siete miembros que conformaron el gabinete constituido por Felipe V en 1724, cuando abdicó en su hijo Luis I. Vid. FAYARD, Janine, Los miembros del Consejo de Castilla, Madrid, Siglo XXI, 1982, pág. 152. 
decreto de 29 de marzo de 1737, acudiera al patrocinio de José Patiño para alcanzar tan alta merced. En el despacho de su título destacaban, entre otros, los servicios que Antonio Álvarez había realizado como paje de Carlos II, teniente general de los reales ejércitos, gobernador político militar de Cádiz y sargento mayor de las Guardias de Corps. No obstante, la influencia de Patiño debió ser determinante, incluso más que los propios méritos del solicitante, quien unos años antes, concretamente en 1733, le había remitido al futuro secretario de Estado una petición para que le favoreciera con «su poderoso y eficaz influjo para que por medio de él afiance la satisfacción de esta gracia» ${ }^{74}$. Entre los mismos papeles de la solicitud, quedó inserta una esquela en la que constaba lo siguiente: «S.E. [José Patiño] hará presente al rey su instancia con deseo de que S.M. condescienda a ella, de que resultara a S.E. una muy singular satisfacción» ${ }^{75}$.

Además del apoyo de Patiño, sería igualmente decisivo para la concesión del título nobiliario el hecho de que la esposa de Antonio Álvarez Bohórquez, Winfreda White Warron, camarista de la reina, hubiera presentado directamente a la soberana el memorial de su esposo solicitando la merced. Winfreda pertenecía a una familia irlandesa con gran influjo en la Corte, pues de la mano de su madre - la marquesa de Albiville_- ella y sus cuatro hermanas habían logrado influyentes puestos como camaristas en $1710^{76}$.

\subsubsection{Compensación de servicios pecuniarios: la compra de títulos nobiliarios}

A través del cruce de diversas fuentes documentales hemos podido constatar que, en algunos casos, por las mismas fechas en que el rey emitía el decreto ejecutivo que otorgaba la merced, había tenido lugar, por parte del agraciado, un pago monetario que constituía el verdadero motivo de la concesión. El abono de la cuantía pudo realizarse de forma directa, en la Tesorería General o en las arcas de quien vendía, o bien de forma indirecta, cediendo a la Real Hacienda créditos que se tuvieran contra ella, o realizando un «servicio en especie», como levantar un regimiento de nueva leva, que igualmente implicaba un gasto para el interesado. En algunas de estas adquisiciones de títulos nobiliarios, donde el servicio pecuniario fue determinante, pudieron alegarse también méritos y servicios —en su mayoría manipulados o intrascendentes-, tanto del solicitante como de sus familiares, para que el desembolso quedara disimulado. Normalmente, estos «méritos y servicios» se hicieron constar en el despacho del título nobiliario, donde a menudo se silenciaba la compra de esta

${ }_{74}$ AHN, Estado, leg. 3473, 17.

75 AHN, Estado, leg. 3473, 17.

76 Vid. ANdújar CASTILlo, Francisco, «Familias irlandesas en el Ejército y en la Corte borbónica», en García Hernán, Enrique; ReCio MORALES, Oscar, (coords.), Extranjeros en el Ejército. Militares irlandeses en la sociedad española, 1580-1818, Madrid, Ministerio de Defensa, 2007, págs. 285-287. 
merced. El deseo expreso - presente en muchas de estas enajenaciones- de que no figurara en ningún lugar el pago realizado es muestra evidente de que los títulos nobiliarios otorgados por dinero podían tener una consideración social inferior a aquellos obtenidos por prestaciones realizadas en la guerra o en el gobierno de la monarquía.

La concesión del título nobiliario de conde de Torrehermosa, en 1706, es un ejemplo de merced nobiliaria otorgada principalmente por la cesión a la hacienda regia de unos créditos que se tenían contra ella, a pesar de que el agraciado, Francisco Hermosa Revilla, alegaría además ser Gentilhombre de Cámara $^{77}$, caballero de la orden de Calatrava ${ }^{78}$, y señor y barón mayor de la casa solariega de Hermosa, en las montañas de Burgos, lo que lo convertía en heredero de la «antigua y notoria nobleza» de su apellido y de los méritos de sus antepasados, principalmente de su abuelo, Vicente de Hermosa. Además, desde 1677 había ejercido como encargado de la administración de las rentas reales en diferentes ciudades y villas de Sevilla, y había sido miembro de la Junta de Cuentas del consulado de aquella ciudad 79 . En 1701, junto con un socio, Antonio Bordas Henestrosa, desarrolló actividades como asentista, encargándose de proveer de pan y cebada a las plazas de Málaga y Gibraltar, y a las tropas de la costa de Granada ${ }^{80}$. En julio de 1702 obtuvo el puesto de proveedor general del ejército y costas de Andalucía, función que le supuso el empeño de parte de su capital para el socorro de las tropas. Un año más tarde —en un claro proceso de ascenso social- decidió hacerse con una veinticuatría de Sevilla, por la que llegó a pagar 30.000 reales de vellón, oficio que ocupó hasta su muerte $^{81}$. Ese mismo año, en 1703 , marchó a la Corte ${ }^{82}$ y dos años más tarde compró el puesto de administrador de las rentas reales de algunas ciudades de Sevilla y de marchamador de la aduana de la misma ciudad ${ }^{83}$.

Su principal mérito - para obtener el título nobiliario - consistió en haber adelantado a la Real Hacienda hasta 18.367.794 maravedís, siendo proveedor general del ejército y las costas de Andalucía. La deuda de la hacienda con su casa de negocios llegó a ascender a una suma superior a los 14.000 doblones $^{84}$. Francisco Hermosa Revilla debió ser consciente de que esos préstamos difícil-

77 AGMJ, leg. 239-3, exp. 2162.

${ }_{78}$ AHN, Órdenes Militares, Caballeros de Calatrava, exp. 1208.

79 Mientras desempeñó este empleo había suplido con su caudal en diversas ocasiones, a petición del rey, por encontrarse el erario sin medios suficientes. AGMJ, leg. 239-3, exp. 2162; también en AGS, Contadurías Generales, leg. 189.

80 AGS, Contadurías Generales, leg. 188.

${ }^{81}$ AGMJ, leg. 239-3, exp. 2162.

82 Morales Moya, Antonio, «Movilidad social en la España del siglo XVIII. Aspectos sociológicos y jurídicos de la concesión de títulos nobiliarios», Revista Internacional de Sociología, 50 (1984), pág. 487.

83 AHN, Consejos, leg. 8976, 182.

${ }^{84}$ AGS, Contadurías Generales, leg. 189. 
mente podrían serle devueltos, y trató de resarcirse cuando entró en contacto con Amelot para negociar la posibilidad de cancelar parte de esos préstamos a cambio de la concesión de un título nobiliario ${ }^{85}$. Que el solicitante recurriera al embajador francés para obtener la merced es compresible si tenemos en cuenta que entre mayo de 1705 y septiembre de 1709, fue Amelot, junto a José Grimaldo, quien estuvo al frente de la operación venal llevada a cabo para sufragar los gastos de la Guerra de Sucesión ${ }^{86}$.

La evidencia de que Amelot intervino como mediador en la concesión de esta merced se refleja en una petición del futuro conde de Torrehermosa en la que solicitaba que se le expidieran los despachos de dicho título ${ }^{87}$. En este documento ha quedado constancia de que, tras los acuerdos entre Francisco Hermosa y Amelot, éste último escribió al marqués de Campollano, Francisco Nicolás Castro, secretario de la secretaría de justicia de la Cámara de Castilla, para que hiciese presente al rey «lo agradable del servicio del suplicante», es decir, para que influyera en la decisión real exponiendo el gran beneficio que los servicios pecuniarios del solicitante habían supuesto para la Real Hacienda. El rey no sólo le concedió el título nobiliario, por decreto de 12 de enero de $1706^{88}$, sino que además quiso recibir a Francisco Hermosa para manifestarle «lo bien servido que se hallaba de este servicio por el amor, celo y lealtad del suplicante». Es evidente que en la concesión de esta merced no sólo fue determinante el «capital económico», sino también el «capital relacional»y, por tanto, el influjo que Amelot o el marqués de Campollano ejercieron sobre la persona y las decisiones del rey.

Otro ejemplo de título nobiliario concedido por decreto ejecutivo tras el desembolso de una cantidad de dinero, a pesar de que también se expondrían méritos para disimular la compra, fue el de marqués de la Encomienda, otorgado a Lorenzo Fernández Flores el 28 de marzo de $1732^{89}$. Según el despacho del título, el agraciado contaba con méritos propios y «heredados de sus familiares». Había servido en la campaña de Niza, en el socorro de Badajoz y Jerez de los Caballeros, y en 1706 había concurrido como caballero de Santiago ${ }^{90}$ al llamamiento que había hecho el rey a todos los caballeros de órdenes para que se unieran al ejército. Además, poseía renta suficiente para mantener con decencia el título nobiliario ${ }^{91}$ - requisito fundamental en las concesiones junto

${ }^{85}$ AGMJ, leg. 239-3, exp. 2162.

86 Vid. ANDÚjar Castillo, Francisco, Necesidad y venalidad..., págs. 83-88.

87 AGMJ, leg. 239-3, exp. 2162.

88 AHN, Consejos, leg. 8976, 182. También en AGS, Estado, lib. 484.

89 AHN, Consejos, leg. 8977, exp. 762. La merced se concedió libre de lanzas y medias anatas perpetuamente, y con la facultad de poder vincularla.

90 Obtuvo el hábito de caballero de esta orden en 1691. AHN, Órdenes Militares, Caballeros de Santiago, exp. 2944.

${ }_{91}$ Contaba su Casa con 7.000 ducados de renta anual. AGS, Secretaría y Superintendencia de Hacienda, leg. 145-2. 
con los méritos y servicios — y formaba parte de una "prestigiosa familia» que estaba emparentada con algunas de las Casas más Ilustres de grandes y titula$\operatorname{dos}^{92}$. En definitiva, una serie de méritos poco relevantes que trataban de «adornar» y justificar la concesión de un título nobiliario, cuyo origen no había sido otro que el desembolso monetario de 165.000 reales, "por cuenta de mayor cantidad», lo que indica que el monto total a pagar por la merced fue superior a esa cifra. La venta de este título nobiliario formó parte de las diferentes gracias y empleos que se enajenaron para financiar el traslado de la Corte a Sevilla en $1729^{93}$. Como solía ser habitual, en el despacho del título nobiliario no se hizo mención alguna a la compra.

Del total de decretos ejecutivos que se emitieron para otorgar un título nobiliario a quien había realizado un desembolso monetario, hubo un alto porcentaje que fue concedido a individuos carentes de méritos que ni siquiera se preocuparon por hacer constar en los despachos de sus títulos algún servicio que disimulara la obtención por la vía del dinero. La falta de méritos y circunstancias en estos individuos explica que el empleo del decreto ejecutivo fuera mayoritario y que el monarca prescindiera entonces de las consultas de la Cámara de Castilla. El objetivo principal del soberano fue aprontar recursos económicos a través de la venta de títulos nobiliarios, por lo que el interés por las calidades de los titulados pasó a un segundo plano, siempre y cuando se abonara la cuantía establecida.

Igualmente, es significativo que la mayoría de los decretos de concesión de títulos nobiliarios, otorgados previo pago de una cantidad de dinero, se dispensaran en coyunturas en las que existió mayor venalidad de cargos y honores - como fue durante la Guerra de Sucesión (1701-1715) o a finales del reinado de Felipe V, en torno a la suspensión general de pagos de 1739-, lo que nos lleva a relacionar la vía ejecutiva con la venalidad, relación que existía ya, al menos, desde el siglo XVII ${ }^{94}$. El uso del decreto ejecutivo aseguraba la obtención de un título nobiliario sin la necesidad de contar con la aprobación de la Cámara, lo que implicó la pérdida de control social por parte de esta institución sobre los nuevos titulados. Se imponía así una dinámica políticoadministrativa en la que los adquirientes de mercedes nobiliarias no tenían que acreditar ni un linaje noble ni grandes servicios a la monarquía. Esta situación favoreció la movilidad social, propiciando el ennoblecimiento de individuos de

92 AHN, Consejos, leg. 8977, 762.

93 Andújar Castillo, Francisco, «Vender cargos y honores. Un recurso extraordinario para la financiación de la Corte de Felipe V», en CASTELlano Castellano, Juan Luis y LópezGuadalupe Muñoz, Miguel Luis, (coords.), Homenaje a Don Antonio Domínguez Ortiz, vol. 3, Granada, Editorial Universidad de Granada, 2008, pág. 102.

94 Esta relación se pone de manifiesto con el decreto de marzo de 1701 que, «al tratar de suspender la venalidad de los cargos de Indias, reconocía como venales todos aquellos que se hubiesen concedido por decreto decisivo con anterioridad a esa fecha». Vid. ANDúJAR Castillo, Francisco, Necesidad y venalidad..., pág. 6. 
dudosas calidades. El continuo aumento del número de titulados llevaría consigo, con el paso del tiempo, una consecuente desvalorización de estas mercedes.

La ausencia de méritos y servicios en el despacho de un título nobiliario ni siquiera ficticios - y la obtención de la merced por medio de la vía del decreto, se convierten así en indicios evidentes de que un título, casi con total seguridad, había sido adquirido mediante un desembolso pecuniario, sobre todo cuando el beneficiario provenía del mundo del comercio o de la minería indiana.

Es el caso, por ejemplo, de Domingo Miranda Llanos, titulado como marqués de Premio Real por decreto ejecutivo de 30 de diciembre de $17400^{95}$. Aparentemente, según la información que aporta el despacho del título nobiliario ${ }^{96}$ y la Gaceta de Madrid ${ }^{97}$ — que publicitó la concesión—, los motivos del ennoblecimiento no habrían sido otros que «su distinguida nobleza y sus señalados servicios, que ha hecho, y está haciendo». Ambos documentos ocultaban una compra-venta privada entre el duque de la Mirándola, quien agobiado por sus deudas había solicitado al rey un título nobiliario en blanco para beneficiar y satisfacer así, con su producto, a sus acreedores ${ }^{98}$, y el referido Domingo Miranda Llanos, un indiano que disponía de un gran capital acumulado a partir de la agricultura, la ganadería y la explotación de minas en Nueva España ${ }^{99}$, parte del cual invertiría en la adquisición de aquella merced que le permitiría titularse desde entonces como marqués de Premio Real ${ }^{100}$. Como ocurría en cualquier proceso venal, fue preciso recurrir a mediadores para llevar a cabo la operación venal. En este caso ejercieron como tales el cardenal Molina, presidente del Consejo de Castilla, y el marqués de la Compuesta, por entonces secretario del Despacho de Gracia y Justicia ${ }^{101}$.

${ }_{95}$ AHN, Consejos, leg. 8978, exp. 809. Esta merced fue concedida libre de lanzas y medias anatas.

96 AHN, Consejos, leg. 8978, exp. 809.

97 Gaceta de Madrid, 17 de enero de 1741.

98 El título en blanco para beneficiar se le concedió libre de lanzas y medias anatas. AGS, Secretaría y Superintendencia de Hacienda, leg. 148; AGS, Secretaría y Superintendencia de Hacienda, leg. 147-1.

99 Faya DíAz, María Ángeles y ANes Fernández, Lidia, Nobleza y poder en la Asturias del Antiguo Régimen, Oviedo, 2007, KRK, pág. 89.

100 Su intención siempre estuvo encaminada desde el primer momento a promocionar socialmente hasta lo más alto de la jerarquía social, pasando por la compra del honor nobiliario, pues tenemos constancia de que antes de llevarse a cabo la negociación con el duque de la Mirándola, trató de adquirir una merced similar a través de una institución eclesiástica, concretamente a través del Convento de Nuestra Señora de Atocha (AGS, Secretaría y Superintendencia de Hacienda, leg. 1471). Prosiguiendo con su ascenso social lograría obtener en 1741 facultad para fundar mayorazgo (AHN, Consejos, lib. 2757) y dos años después, el hábito de caballero de la orden militar de Santiago (FAYA DíAZ, María Ángeles y ANES FernándeZ, Lidia, Nobleza y poder..., pág. 40).

${ }_{101}$ AGS, Secretaría y Superintendencia de Hacienda, leg. 147-1. 


\section{CONCLUSIONES}

El empleo casi sistemático del decreto ejecutivo y los escasos memoriales que fueron remitidos a la Cámara de Castilla para que los consultara provocaron que esta institución quedara marginada del proceso de concesión de los títulos nobiliarios. El rey, incluso llegaba a prescindir del parecer de la Cámara cuando esta comprobaba que un individuo no era digno de ser ennoblecido, por faltarle las calidades requeridas, concediéndole años más tarde el título de conde o marqués por decreto ejecutivo. Los criterios del rey acerca de quienes debían ser los nuevos Títulos de Castilla debieron depender más de sus propios intereses o de la influencia de determinadas personas de su entorno más cercano, que de las cualidades de los futuros titulados. No deja de resultar contradictorio que el monarca, por un lado, remitiera a la Cámara memoriales de solicitud de títulos nobiliarios para que le informara acerca de las circunstancias de los pretendientes, mientras que por otro, ennoblecía a numerosos individuos de «dudosa calidad» a través de la vía del decreto ejecutivo. El hecho de que en un momento determinado pidiera a la Cámara que velase por la naturaleza de los solicitantes debió ser algo excepcional, al igual que la remisión — por parte del rey- de los memoriales a la Cámara para que los consultara y diera su parecer sobre ellos, por lo que el empleo del decreto ejecutivo se iría imponiendo progresivamente frente a las consultas de la Cámara.

Lo más significativo es que a diferencia de otros honores inferiores de la escala nobiliaria, como fueron la hidalguía o los hábitos de las órdenes militares, para hacerse con un Título de Castilla no hubo que alegar grandes méritos y servicios, sangre noble u otras calidades. Las pruebas para conseguir un hábito de caballero de cualquier orden militar, o para obtener una ejecutoria de hidalguía, conllevaron largos procesos que, al menos en teoría, implicaban un conocimiento exhaustivo de las calidades del peticionario y sus familiares, a pesar de que algunos orígenes sociales fueron manipulados e inventados. Sin embargo, para la obtención de un título nobiliario bastó con remitir un memorial de petición al rey, exponiendo fundamentalmente los servicios propios y heredados, y las rentas que se poseían, o incluso ni eso, como ocurrió con los títulos que fueron directamente otorgados por decreto ejecutivo, sin haber precedido más mérito que el servicio pecuniario.

Cabe destacar, que las pretensiones de títulos nobiliarios que fueron consultadas por la Cámara de Castilla fueron sometidas a un mayor control social que aquellas que no circularon por esta vía, ya que normalmente la Cámara solía despachar cédulas de diligencias para conocer las circunstancias que concurrían en los solicitantes. No obstante, como hemos expuesto más arriba, en muchas ocasiones ese supuesto control que se ejercía sobre los aspirantes fue más ficticio que otra cosa, máxime si había mediado un desembolso monetario. Por otro lado, si la mayoría de los títulos nobiliarios se concedieron por decreto ejecutivo, es evidente que la observancia ejercida sobre los orígenes sociales de los 
nuevos titulados fue muy reducida, lo cual favorecería sobre todo a aquellos individuos que provenían del mundo del comercio, la minería u otras actividades financieras, que no tuvieron que acreditar procedencias ilustres ni pasar por filtro social alguno. Ante la progresiva incorporación a la nobleza titulada de personas de dudosas calidades - en su mayoría, los que obtenían el título nobiliario por compra-, un decreto de 14 de febrero de $1749^{102}$ ordenó que no se diese curso a las solicitudes de Títulos de Castilla que estuviesen concedidos o se concediesen en adelante para beneficiar - léase, vender-, sin dar primero cuenta al rey de las «circunstancias de los pretendientes». Para entonces, el uso del decreto ejecutivo había permitido ya a un importante número de individuos ascender hasta la nobleza titulada, sin contar, en muchos casos, con más calidades o servicios que los pecuniarios.

Recibido: 01-10-2009

Aceptado: 30-06-2010

102 AGS, Secretaría y Superintendencia de Hacienda, leg. 150. 